\title{
Expression and localization of prominin-1 in isoproterenol-treated rat parotid gland
}

\author{
FABIO D'AMICO, EVANGELIA SKARMOUTSOU, KATIA MANGANO, GRAZIA MALAPONTE, \\ FRANCA STIVALA and MARIA CLORINDA MAZZARINO
}

Department of Biomedical Sciences, University of Catania, Catania, Italy

Received May 25, 2010; Accepted June 28, 2010

DOI: 10.3892/ijmm_00000492

\begin{abstract}
Prominin-1 (CD133) is a pentaspan cholesterolbinding membrane glycoprotein. Chronic treatment with isoproterenol, a ß-receptor agonist, induces several dramatic effects on salivary glands, such as enhanced DNA synthesis and proliferation of salivary acinar cells. In addition, the biosynthetic pathways of membrane lipids may be altered by the isoproterenol stimulation. The purpose of this study was to investigate the effect of isoproterenol administration on prominin-1 expression profiles in rat parotid gland by means of PCR and immunohistochemistry. Rats were chronically treated with the $\beta$-adrenergic agonist for 1,3 , and 7 days. Our results showed that isoproterenol-treatment caused a downregulation of prominin- 1 on day 3 and 7 of treatment, as well as a differential immunostaining distribution pattern. This study suggests that isoproterenol-treatment may represent a useful tool to explore the molecular mechanisms involved in the synthesis and release of prominin-1. Such efforts could contribute to the development of diagnostic tools based on the detection of prominin-1 in biological fluids, such as saliva.
\end{abstract}

\section{Introduction}

Prominin-1 (CD133) is a pentaspan cholesterol-binding membrane glycoprotein belonging to the prominin family (1). Mammalian prominin-1 is broadly expressed in many embryonic and adult tissues (2-4), and it is specifically associated with plasma membrane evaginations, such as microvilli and stereociglia. Moreover, biological fluids, such as saliva and tears, are enriched in prominin-1, which is associated with small membrane vesicles $(2,5-8)$. The functions and ligands of the prominins are still unclear and elusive, and little is known about mechanisms involved in delivery of prominin-1 to cell membrane (9). Now it is emerging that prominin-1 may have an important role in the regulation of

Correspondence to: Dr Fabio D'Amico, Department of Biomedical Sciences, University of Catania, via Androne 83, 95124 Catania, Italy

E-mail: f.damico@unict.it

Key words: prominin-1, CD133, isoproterenol, parotid gland, immunohistochemistry plasma membrane structure, maintaining an appropriate lipid composition (1). Finally, prominin-1 has been shown to be a potential marker for cancer stem cells in several tumours (10).

In mammalian salivary glands, the stimulation of $\beta$ adrenergic receptors promotes protein secretion, postnatal development and growth (11). Activation of $\beta$-adrenergic receptor causes the production of cAMP and the activation of cAMP-dependent protein kinases, stimulating several cascades, such as MAPKs (12).

It is well known that the treatment with the $\beta$-adrenergic agonist isoproterenol causes enhanced DNA synthesis and proliferation of salivary acinar cells, which leads to hyperplastic and hypertrophic gland enlargement $(13,14)$. Furthermore, isoproterenol administration may alter the biosynthetic pathways of membrane lipids (15).

The purpose of this study was to investigate the effect of isoproterenol on prominin-1 expression profiles in rat parotid gland by means of PCR and immunohistochemistry. Rats were chronically treated with the $\beta$-adrenergic agonist for 1 , 3 , and 7 days.

\section{Materials and methods}

Materials. d,1 Isoproterenol was obtained from Sigma Chemicals Co. (St. Louis, MO). Female Wistar rats, weighing 180-200 g each, were purchased from Harlan (Italy). Polyclonal rabbit antibody to prominin-1 (ab19898) was purchased from Abcam (UK).

Animal treatment and tissue preparation. Sets of female Wistar rats $(n=5)$ received single daily (between 8 and 9 a.m.) intraperitoneal injections of isoproterenol at a dose of $25 \mathrm{mg} / \mathrm{kg}$ body weight, at days $0,1,3$, and 7 . Control animals received injections of $0.5 \mathrm{ml}$ saline under the same regimen of treatment. Animals were kept under standard laboratory conditions (non-specific pathogen-free) with food and water ad libitum. Twenty-four hours after the last dose, rats were euthanized by carbon dioxide inhalation and parotid glands were excised, trimmed of fat and lymph nodes washed with PBS (pH 7.4), weighed and immediately fixed in buffered $3.7 \%$ (para) formaldehyde, $\mathrm{pH} 7.4$, for $24 \mathrm{~h}$. After washing and dehydration, specimens were embedded in paraffin. The handling of animals and the study protocol were in accordance with international guidelines and approved by the local Institutional Animal Care and Use Committee. 
RNA preparation and RT-PCR analysis of $m R N A$ expression. Total RNA was isolated from paraffin sections of parotid gland tissue (10 $\mu \mathrm{m}$ thickness) by using the PureLink FFPE Total RNA Isolation kit (Invitrogen, Carlsbad, CA, USA), according to the manufacturer's instructions. After treatment with DNase I (Invitrogen), reverse transcription reaction and PCR amplification were performed with Eppendorf AG22331 (Hamburg, Germany) thermal cycler reactor. Total RNA $(1.4 \mu \mathrm{g})$ was heated at $65^{\circ} \mathrm{C}$ for $5 \mathrm{~min}$ and then cooled on ice. It was combined with $0.15 \mu \mathrm{g}$ of random primers (Invitrogen), transcription buffer, RNase OUT (40 U/ $\mu 1$; Invitrogen), dNTPs (10 mM each) and M-MLV reverse transcriptase (200 U; Invitrogen) in a final volume of $20 \mu 1$. Incubation was performed at $37^{\circ} \mathrm{C}$ for $50 \mathrm{~min}$.

Amplification were performed with $3 \mu \mathrm{l}$ cDNA in a total volume of $50 \mu \mathrm{l}$ containing $200 \mathrm{mM}$ Tris- $\mathrm{HCl}, \mathrm{pH} 8.4,500 \mathrm{mM}$ $\mathrm{KCl}, 50 \mathrm{mM} \mathrm{MgCl} 2,10 \mathrm{mM}$ dNTP mix, $10 \mu \mathrm{M}$ of specific primers and $5 \mathrm{U} / \mu 1$ of Taq DNA polymerase (Invitrogen). Primer pairs of rat prominin-1 were: FW: 5-ATCTGGCTC CGAGTGCTTGCC-3; RV: 5-ATCATAGCCAGAGATGG ATACC-3. For semi-quantative amplification each cycle were carried out at $93^{\circ} \mathrm{C}$ for $60 \mathrm{sec}, 64^{\circ} \mathrm{C}$ for $60 \mathrm{sec}$, and $72^{\circ} \mathrm{C}$ for $60 \mathrm{sec}$. The reaction was stopped after 35 cycles. Normalisation was performed by RT-PCR amplification of glucose6-phosphate dehydrogenase (G6PD). The sequences of these primers were: FW: 5-ACGTGATGCAGAACCACCTA CTG-3; RV: 5-ACGACGGCTGCAAAAGTGGCG-3. The amplified products were obtained as described for prominin-1. PCR product were separated on a $2 \%$ agarose gel, stained with ethidium bromide, and photographed under ultraviolet illumination.

For quantitation, gels were scanned, and the pixel intensity for each band was determined using the Quantity-One software (Bio-Rad, Richmond, CA, USA) and normalized to the amount of glyceraldehyde-3-phosphate dehydrogenase (GAPDH). All values were determined in triplicate. Negative controls consisting of RNase-free water substituted for template cDNA, were included to ensure no crossover DNA contamination.

Immunohistochemistry. Five- $\mu \mathrm{m}$-thick sections from paraffin-embedded tissue blocks were placed on silanized slides. After section deparaffinization and rehydration through a graded ethanol series at room temperature, antigen retrieval was performed in citrate buffer $(\mathrm{pH}$ 6.0) for $30 \mathrm{~min}$ at $95^{\circ} \mathrm{C}$ using a water bath. Then, sections were treated with $0.3 \%$ hydrogen peroxide for $15 \mathrm{~min}$ at room temperature to quench the endogenous peroxidase activity, and incubated with diluted normal blocking serum for $20 \mathrm{~min}$ at room temperature. Subsequently, the sections were incubated with rabbit polyclonal primary antibodies anti-prominin-1, diluted 1:200, for $1 \mathrm{~h}$ at room temperature. After washing with phosphate buffered saline, the detection was carried out using the streptavidin-biotin-peroxidase complex system (Immuno Cruz $^{\mathrm{TM}}$ Staining System; SantaCruz Biotechnology Inc., Santa Cruz, CA, USA), according to the manufacturer's instructions. Finally, sections were counterstained with Mayer's hematoxylin. Slides were mounted and observed by conventional light microscopy. Negative control experiments were performed substituting the primary antibody with non immune serum and by omitting the primary antibody, thus

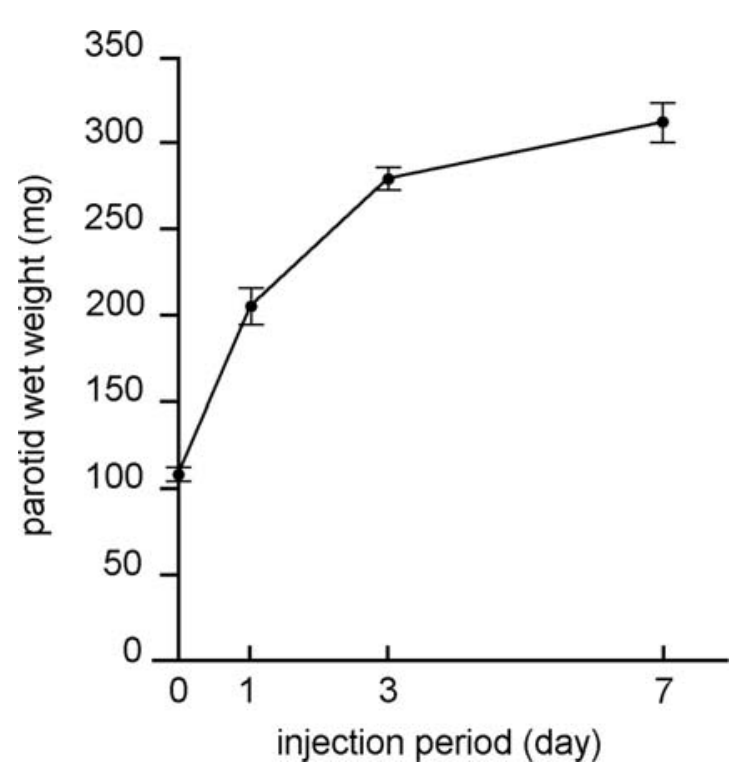

Figure 1. Changes in weight of parotid glands during the isoproterenol treatment. The most striking increase occurs between 0 and 3 days of treatment. Each value was statistically significant $(\mathrm{p}<0.05)$.Values are expressed as mean $\pm \mathrm{SD}$.

incubating slides only with buffer. For standard histological evaluation, sections were also stained with hematoxylin-eosin.

Image analysis. Immunolabelled and random systematically sampled sections were observed using a Leica DMRB microscope (Leica, Wetzlar, Germany) and photographed with a Canon G-9 camera (Canon, Japan). All images were obtained using a $\mathrm{x} 40$ objective. A total of 30 fields were analyzed using ImageJ software, version 1.42g (16). Immunolabelling intensity was analyzed with the colour deconvolution plug-in (17). Subsequently, the immunostained fraction area ( $f a$ ) was used (percent area) according the following formula:

$$
F a=\frac{\sum S a}{\sum A}
$$

where $S a$ is the stained area, $A$ is the total area of the image field.

Statistical analysis. For mass gland measurements, semiquantitative RT-PCR and immunohistochemical analysis, statistics was performed by using the unpaired Student's t-test. Differences were considered statistically significant at a level of $\mathrm{p}<0.05$.

\section{Results}

Parotid mass increase and histological findings of the parotid gland during isoproterenol treatment. As shown in Fig. 1, parotid gland wet weight markedly increased from 0 to 7 days of treatment. The overall increase was of $196 \%$ $(\mathrm{p}<0.01)$. Mass increase between 0 and 1 day was approximately $97 \%$, between 1 and 3 days was about $35 \%$, and between 3 and 7 days was about $11 \%(\mathrm{p}<0.05)$. The most striking increase in weight was observed between 0 and 3 days of treatment. 

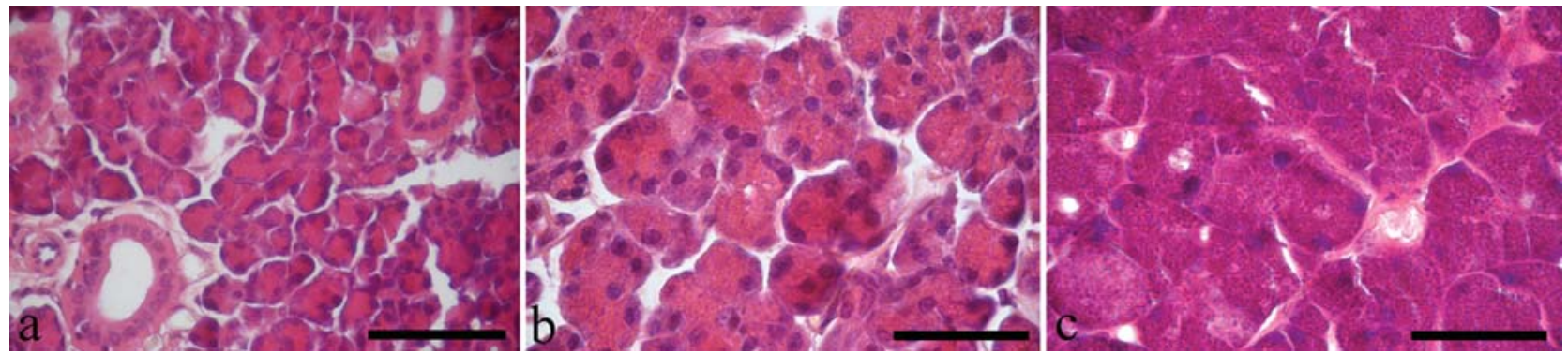

Figure 2. Representative micrographs of histological changes in normal (a; bar: $100 \mu \mathrm{m}$ ) and isoproterenol parotid glands (b and c; bars: $60 \mu \mathrm{m})$ stained with hematoxylin and eosin. The size of acinar cells is increased by isoproterenol treatment at day 1 and 7 (b and c, respectively).

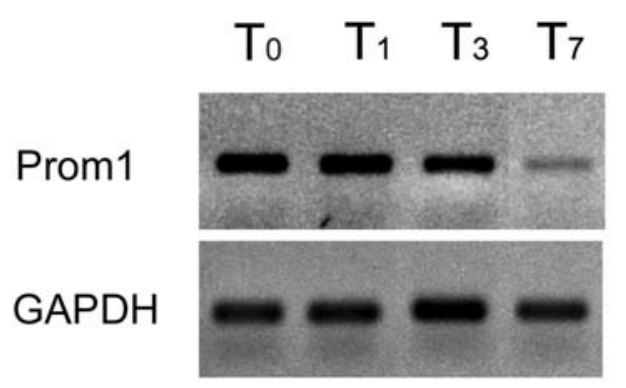

a
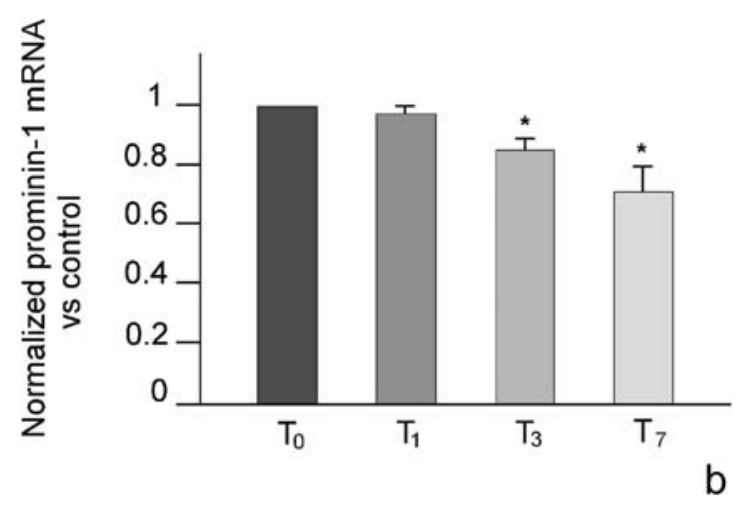

Figure 3. Expression of prominin-1 mRNA in normal and isoproterenoltreated rat. Representative blots (a) and densitometric quantification of mRNA expression normalized by GAPDH levels (b). Isoproterenol treatment induces a decrease of prominin-1 mRNA expression from day 3 of treatment. Histograms bars correspond to treatment days $0,1,3$, and 7, respectively. Values are expressed as mean \pm SEM. ${ }^{*} \mathrm{P}<0.05$ vs. control.

Fig. 2 shows a representative morphological comparison between H\&E stained sections of normal parotid gland tissue and isoproterenol-treated glands. The main effect of isoproterenol was the enlargement of the acinar cells, because of the increased number of secretory granules.

Semiquantitative analysis of $m R N A$ expression of prominin-1 in normal and isoproterenol treated rat parotid gland. The results of PCR assay are summarized in Fig. 3. The levels of mRNA were given as relative amounts with normalization against GAPDH. Expression of prominin-1 was revealed in normal parotid glands as well as in isoproterenol-treated tissues. However, there was a time-dependent and inhibitory effect of isoproterenol treatment on prominin expression. In fact, a significant decrease of prominin-1 expression to approximately $84 \%$ and $70 \%$ of control values $(\mathrm{p}<0.05)$ was observed in treated rats after 3 and 7 days of treatment, respectively $(\mathrm{p}<0.05)$.

Immunohistochemical localization of prominin-1 in normal and isoproterenol treated rat parotid gland. Immunohistochemical localization of prominin-1 in normal and isoproterenol-treated rat parotid glands is shown in Fig. 4. Both untreated and treated glands express prominin-1. In normal parotid, prominin-1 was mainly localized on the apical and lateral surfaces of acinar cells (Fig. 4a), as well as in their cytoplasm. In addition, ductal epithelial cells showed a discrete immunostaining at the apical membrane facing the lumen (Fig. 4b). On day 1 of treatment with isoproterenol, acinar cells showed a similar immunostaining pattern in comparison to the untreated tissue: prominin-1 was observed at cytoplasmic level and, although less frequently, over apical and lateral cell membrane domains (Fig. 4c). Ducts epithelial cells maintained their characteristic staining pattern as in untreated glands (inset of Fig. 4c). On days 3 and 7 of treatment (Fig. 4d and e, respectively), parotid acinar cells exhibited a discrete immunostaining in their secretory granules, localized on their membranes (Fig. 4d). However, at 7 days of treatment the duct luminal surface seemed to be unstained for the protein (Fig. 4e). Appropriate negative controls showed no immunoreaction (Fig. 4f).

As showed in Fig. 5, semi-quantitative image analysis of immunohistochemical results showed that isoproterenol treatment induced a decreased expression of prominin-1. In particular, significant decreases $(\mathrm{p}<0.05)$ of prominin-1 expression were observed after 3 and 7 days of treatment (42\% and $52 \%$ of control value, respectively).

\section{Discussion}

We described here the expression profiles of prominin-1 in normal and isoproterenol-treated rat parotid gland. The main localization of prominin-1 in the apical and basal membrane domains of acinar cells, as well as, in membrane of ductal epithelial cells facing the lumen, is in accordance with the known topological occurrence of prominin-1 in various plasmalemmal protrusions (2). It is know, in fact, that apical and lateral free surfaces of acinar cells of salivary gland 

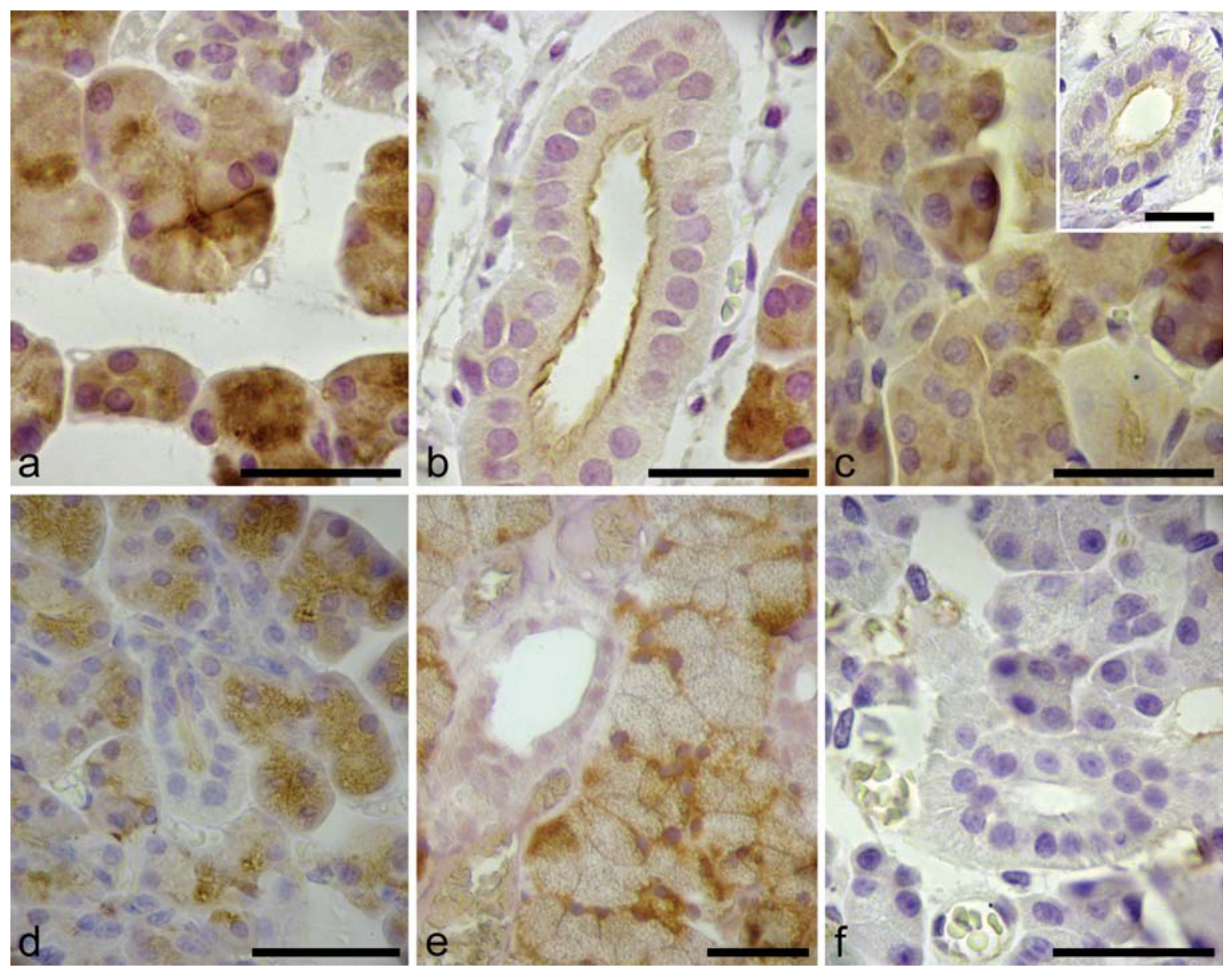

Figure 4. Immunolocalization of prominin-1 in normal and isoproterenol-treated rat parotid gland. In normal rat parotid gland, prominin-1 is mainly localized on the apical and lateral zones of acinar cells. In addition, the cytoplasm of acinar cells is immunolabelled (a). Ductal epithelial cells of untreated gland show discrete immunostaining at the apical membrane facing the lumen (b). After 1 day of treatment with isoproterenol, acinar cells show a similar staining pattern in comparison to the untreated tissue: a cytoplasmic staining for the prominin-1, and, although less frequently, a staining over the apical and lateral zones of acinar cells (c). The ducts maintain their characteristic staining pattern as in untreated glands (c, inset). At days 3 and 7 of treatment (d and e, respectively), prominin-1 immunostaining is mainly localized over membranes of secretory granules in acinar cells. However, at 7 days of treatment the duct luminal surface seems to be unstained for the protein under study (e). A representative micrograph of a negative control in untreated tissue is shown (f). [bars: $50 \mu \mathrm{m}$, except for inset $(25 \mu \mathrm{m})]$.

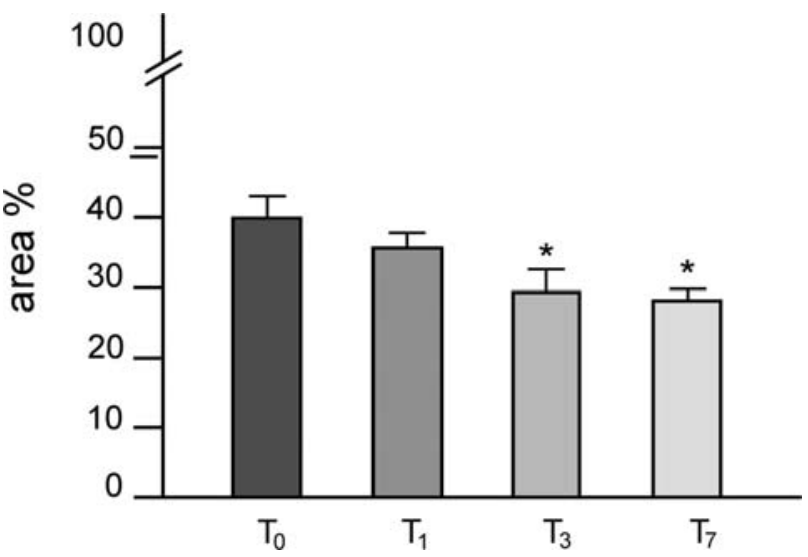

Figure 5. Semi-quantitative image analysis of prominin-1 immunolabelling (area density) in normal and isoproterenol treated rat parotid gland. Isoproterenol treatment induces a decreased expression of prominin-1. Significant decreases are observed after 3 and 7 days of treatment (approximately $42 \%$ and $52 \%$ of control value, respectively). Histograms bars correspond to treatment days $0,1,3$, and 7 , respectively. Values are expressed as mean and standard errors. ${ }^{\mathrm{p}} \mathrm{p}<0.05$ vs. control. contain such protrusions (18). In particular, prominin-1 has been recently immunolocalized on human and mouse parotid glands $(19,20)$. Furthermore, many other duct epithelia, such as those of pancreas, mammary gland lactiferous and epididymal ducts, contain this molecule $(21,22)$. The major finding of this study was that isoproterenol-treatment caused a time-dependent downregulation of prominin-1 mRNA and protein, as well as, a different immunostaining distribution pattern.

It is known that, among the dramatic effects of isoproterenol administration, there are an alteration of the biosynthetic pathways of membrane lipids (15), as well as, a cell damage in rodent salivary glands, with an appearance of large lipid droplets within cells (23). Since it is known that sorting of prominin-1 involves a cholesterol-based lipid raft (24), and that 3 -adrenergic receptors are dynamically associated with membrane rafts (25), the disturbing effect of isoproterenol on lipid biochemistry could result in the decreased transcription and expression of prominin-1. On days 3 and 7 of treatment with the $\beta$-agonist, prominin- 1 is mainly localized over secretory granule membranes of acinar 
cells. Such induced change in protein distribution could be due to the isoproterenol treatment, which would alter the mechanisms of the regulated secretion in rat parotid glands, with a consequent routing of apical secretion pathway to the basolateral one (26). Moreover, changes in cell polarity have been shown to occur in salivary acinar cell treated with isoproterenol (27), and prominin-1 has been suggested to influence cell polarity (9). Finally, experimentally induced changes in lipid composition, such as in cholesterol, was found alter the release of membrane vesicle containing prominin-1 in Caco-2 cells $(7,28)$.

In addition to differentiated cells, the turnover of salivary glands may be ensured by a stem cell population, and prominin-1 has been shown to be a marker for stem cell in several tissues $(5,29-31)$. However, our study shows that prominin-1 is not restricted to a single cell population and its expression is broadly localized among the acinar and ductal cells. Thus, we can conclude that prominin-1 is not a suitable marker for stem cell in parotid gland. For this reason other molecules, such as keratin 18 (K18), $\alpha$-smooth muscle actin ( $\alpha$-SMA), achaete scute homolog like 3(Ascl3), DNp63, PSCA (prostate stem cell antigen), stem cell antigen-1(Sca-1), c-Kit, Musashi-1, are more suitable markers or promising candidates for stem cell population in salivary glands (32-35). However, the differences of staining patterns of prominin-1 between normal and isoproterenol-treated glands may reflect a different stage of differentiation induced by the $\beta$-agonist.

In conclusion, our study suggests the isoproterenol treatment may represent a useful tool to explore the molecular mechanisms involved in the synthesis and release of the membrane vesicles containing prominin-1. Such efforts could contribute to the development of diagnostic tools based on the detection of prominin-1 in biological fluids, such as saliva. In fact, recent investigations suggest the presence of an association between the release of prominin-1 from cells and several diseases (1).

\section{References}

1. Corbeil D, Marzesco AM, Fargeas CA and Huttner WB: Prominin-1: a distinct cholesterol-binding membrane protein and the organisation of the apical plasma membrane of epithelial cells. Subcell Biochem 51: 399-423, 2010.

2. Weigmann A, Corbeil D, Hellwig A and Huttner WB: Prominin, a novel microvilli-specific polytopic membrane protein of the apical surface of epithelial cells, is targeted to plasmalemmal protrusions of non-epithelial cells. Proc Natl Acad Sci USA 94: 12425-12430, 1997

3. Corbeil D, Röper K, Hellwig A, Tavian M, Miraglia S, Watt SM, Simmons PJ, Peault B, Buck DW and Huttner WB: The human AC133 hematopoietic stem cell antigen is also expressed in epithelial cells and targeted to plasma membrane protrusions. J Biol Chem 275: 5512-5520, 2000.

4. Corbeil D, Joester A, Fargeas CA, Jászai J, Garwood J, Hellwig A, Werner HB and Huttner WB: Expression of distinct splice variants of the stem cell marker prominin-1 (CD133) in glial cells. Glia 57: 860-874, 2009.

5. Miraglia S, Godfrey W, Yin AH, Atkins K, Warnke R, Holden JT, Bray RA, Waller EK and Buck DW: A novel fivetransmembrane hematopoietic stem cell antigen: isolation, characterization, and molecular cloning. Blood 90: 5013-5021, 1997.

6. Fargeas CA, Fonseca AV, Huttner WB and Corbeil D: Prominin-1 (CD133) - from progenitor cells to human diseases. Future Lipidol 1: 213-225, 2006.
7. Marzesco AM, Wilsch-Bräuninger M, Dubreuil V, Janich P Langenfeld K, Thiele C, Huttner WB and Corbeil D: Release of extracellular membrane vesicles from microvilli of epithelial cells is enhanced by depleting membrane cholesterol. FEBS Lett 583: 897-902, 2009.

8. Dubreuil V, Marzesco AM, Corbeil D, Huttner WB and WilschBräuninger $M$ : Midbody and primary cilium of neural progenitors release extracellular membrane particles enriched in the stem cell marker prominin-1. J Cell Biol 176: 483-495, 2007.

9. Shmelkov SV, St Clair R, Lyden D and Rafii S: AC133/ CD133/Prominin-1. Int J Biochem Cell Biol 37: 715-719, 2005.

10. Mizrak D, Brittan M and Alison MR: CD133: molecule of the moment. J Pathol 214: 3-9, 2008.

11. Barka T: $\beta$-Adrenergic effects on salivary glands: growth and gene regulation. Acta Histochem Cytochem 23: 245-255, 1990.

12. Quissell DO, Watson E and Dowd F: Signal transduction mechanisms involved in salivary gland regulated exocytosis. Crit Rev Oral Biol Med 3: 83-107, 1992.

13. Selye HR, Veilleux R and Cantin M: Excessive stimulation of salivary gland growth by isoproterenol. Science 133: 44-45, 1961.

14. Lillie JH and Han SS: Secretory protein synthesis in the stimulated rat parotid gland. Temporal dissociation of the maximal response from secretion. J Cell Biol 59: 708-721, 1973.

15. Yashiro K, Kameyama Y, Mizuno M and Yokota Y: Alteration of membrane phospholipids in hypertrophied rat salivary glands induced by chronic administration of isoproterenol. Arch Oral Biol 32: 799-805, 1987.

16. Rasband WS: ImageJ, US National Institutes of Health, Bethesda, MD, USA, http://rsb.info.nih.gov/ij, 1997-2009.

17. Ruifrok AC and Johnston DA: Quantification of histochemical staining by color deconvolution. Anal Quant Cytol Histol 23: 291-299, 2001.

18. D'Amico F and Skarmoutsou E: Immunolocalization of Ecadherin and $\alpha E$-catenin in rat parotid acinar cell under chronic stimulation of isoproterenol. Arch Oral Biol 52: 161$167,2007$.

19. Jászai J, Janich P, Farkas LM, Fargeas CA, Huttner WB and Corbeil D: Differential expression of Prominin-1 (CD133) and Prominin-2 in major cephalic exocrine glands of adult mice. Histochem Cell Biol 128: 409-419, 2007.

20. Karbanová J, Missol-Kolka E and Fonseca AV: The stem cell marker CD133 (Prominin-1) is expressed in various human glandular epithelia. J Histochem Cytochem 56: 977-993, 2008.

21. Fargeas CA, Joester A, Missol-Kolka E, Hellwig A, Huttner WB and Corbeil D: Identification of novel prominin-1/CD133 splice variants with alternative C-termini and their expression in epididymis and testis. J Cell Sci 117: 4301-4311, 2004.

22. Lardon J, Corbeil D, Huttner WB, Ling Z and Bouwens L: Stem cell marker prominin-1/AC133 is expressed in duct cells of the adult human pancreas. Pancreas 36: E1-6, 2008.

23. Simson JA: Evidence of cell damage in rat salivary glands after isoproterenol. Anat Rec 173: 437-451, 1972.

24. Roper K, Corbeil D and Huttner WB: Retention of prominin in microvilli reveals distinct cholesterol-based lipid microdomains in the apical plasma membrane. Nat Cell Biol 2: 582 $592,2000$.

25. Willoughby D and Cooper DM: Organization and $\mathrm{Ca}^{2+}$ regulation of adenylyl cyclases in cAMP microdomains. Physiol Rev 87: 965-1010, 2007.

26. Venkatesh SG, Tan J, Gorr SU and Darling DS: Isoproterenol increases sorting of parotid gland cargo proteins to the basolateral pathway. Am J Physiol Cell Physiol 293: C558-C565, 2007.

27. Tamaki $\mathrm{H}$ and Yamashina $\mathrm{S}$ : Changes in cell polarity during mitosis in rat parotid acinar cells. J Histochem Cytochem 39: 1077-1087, 1991

28. Hansen GH, Niels-Christiansen LL, Thorsen E, Immerdal L and Danielsen EM: Cholesterol depletion of enterocytes. Effect on the Golgi complex and apical membrane trafficking. J Biol Chem 275: 5136-5142, 2000.

29. Yin AH, Miraglia S, Zanjani ED, Almeida-Porada G, Ogawa M, Leary AG, Olweus J, Kearney J and Buck DW: AC133, a novel marker for human hematopoietic stem and progenitor cells. Blood 90: 5002-5012, 1997. 
30. Rizzo S, Attard G and Hudson DL: Prostate epithelial stem cells. Cell Prolif 38: 363-374, 2005.

31. Corti S, Nizzardo M, Nardini M, Donadoni C, Locatelli F, Papadimitriou D, Salani S, Del Bo R, Ghezzi S, Strazzer S, Bresolin N and Comi GP: Isolation and characterization of murine neural stem/progenitor cells based on Prominin-1 expression. Exp Neurol 205: 547-562, 2007.

32. Kawanami T, Matsuzaki Y, Sawaki T, Sakai T, Jin ZX, Masaki Y, Fukushima T, Tanaka M and Umehara H: Identification of human salivary stem cells from cultured labial minor salivary cells. Nihon Rinsho Meneki Gakkai Kaishi 30: 455-460, 2007.
33. Bullard T, Koek L, Roztocil E, Kingsley PD, Mirels L and Ovitt CE: Ascl3 expression marks a progenitor population of both acinar and ductal cells in mouse salivary glands. Dev Biol 320: 72-78, 2008.

34. Kimoto M, Yura Y, Kishino M, Toyosawa S and Ogawa Y: Label-retaining cells in the rat submandibular gland. J Histochem Cytochem 56: 15-24, 2008.

35. Lombaert IM, Brunsting JF, Wierenga PK, Faber H, Stokman MA, Kok T, Visser WH, Kampinga HH, de Haan G and Coppes RP: Rescue of salivary gland function after stem cell transplantation in irradiated glands. PLoS One 30: E2063, 2008. 